\title{
Does Healthcare Moderate the Impact of Socioeconomic Status on Self- rated Health?
}

Eline Aas*, Annette Alstadsæter and Eli Feiring

Department of Health Management and Health Economics, Institute for Health and Society, University of Oslo, Norway

\begin{abstract}
Background: Empirical evidence is growing for the fact that societal conditions are major causes of differences in health across individuals and societies. A positive correlation between socioeconomic status and health outcomes is documented in countries with various welfare arrangements, level of social trust, and health policies. We investigated how the health gradient was affected by healthcare intervention.

Methods: Self-reported data on health status after exposure to healthcare intervention was collected by means of a postal survey (2009) to all members of the Norwegian Breast Cancer Association. Response rate was 62 percent. 1666 women aged 40-69 was included in the analysis. In order to create a counterfactual framework, we used propensity score analysis to match each observation in the treatment sample with an observation in a non-treatment sample. The observations were classified into high and low socioeconomic status groups based on information on education and labor market affiliation.

Results and conclusion: A social gradient in self-rated health was found. Experience of breast cancer and treatment was shown to have a moderating effect on the gradient. While high-status women on average reported a 0.63 points reduction in health after breast cancer treatment, the corresponding reduction for low status women was 0.32 points. These results lend some support to the hypothesis that individuals from lower status groups may benefit from healthcare more than others due to effects of information and support.
\end{abstract}

Keywords: Cancer treatment; Equity; Health gradient; Propensity score; Social capital

\section{Introduction}

Empirical evidence is growing for the fact that health outcomes are positively correlated with socioeconomic status [1-3]. The social gradient in health exists both in developing and developed societies. Even within affluent countries with small income gaps, extensive welfare provisions, and universal access to high quality healthcare, persistent socioeconomic inequalities in health are reported [4-7]. Social patterning of ill-health is causing political worries, and there is a government policy emphasis on reducing inequity in health in many countries. This has led to a revival of research on the various social determinants of health, such as income and wealth, education, social hierarchies, social capital, and working conditions, calling for policy initiatives on a range of different policy areas. Still, little empirical research has been done on the role of healthcare in the relationship between socioeconomic status and health. One reason may be that similarity between treatment options among different socioeconomic groups are hard to obtain and therefore difficult to compare. In many countries, both access to and use of high quality healthcare is to a large degree socially determined. So, it would be difficult to estimate an "independent" effect of healthcare when patients in different healthcare arrangements have inherently different socioeconomic characteristics.

The aim of the present study was to investigate whether exposure to healthcare alters the social gradient in health. Inspired by the theoretical existing research [8], we hypothesize that the compensating impact of healthcare may be relatively more important to individuals with low socioeconomic status. The driving mechanism behind this is that individuals with low socioeconomic status may have less ability to find adequate information and support on their own. Our theoretical point of departure is shown in Figure 1. Healthcare provides care and psychosocial support, and channels health information which in turn may change health behavior [9]. According to the argument, social capital (the density of trust, networks, or cooperation within a geographical area, e.g. [10]) can enhance information on healthy

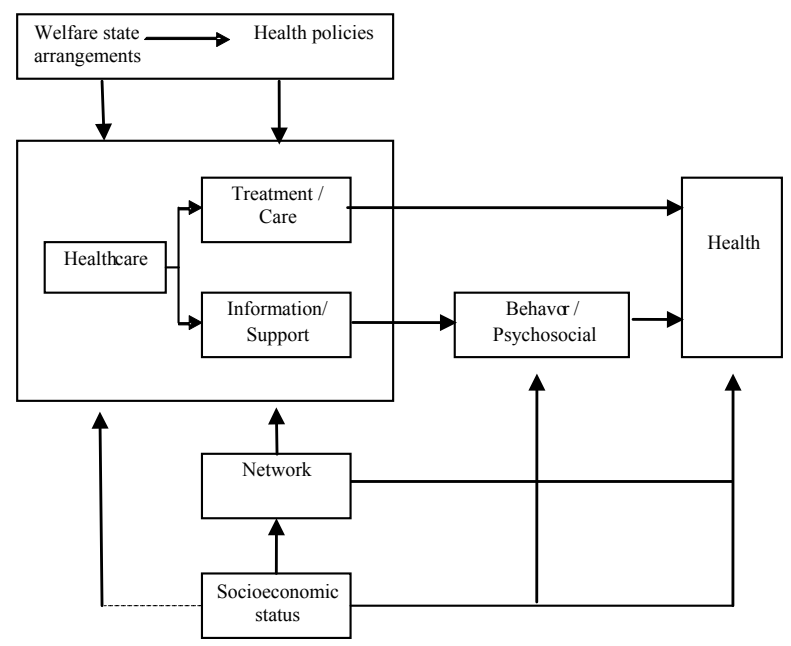

Figure 1: Conceptual framework.

*Corresponding author: Eline Aas, Department of Health Management and Health Economics, Institute for Health and Society, University of Oslo, Norway, Tel: +47 22845100; Fax: +47 22845091; E-mail: eline.aas@medisin.uio.no

Received October 10, 2013; Accepted November 29, 2013; Published December 10,2013

Citation: Aas E, Alstadsæter A, Feiring E (2013) Does Healthcare Moderate the Impact of Socioeconomic Status on Self-rated Health? J Clin Res Bioeth 5: 169. doi:10.4172/2155-9627.1000169

Copyright: (c) 2013 Aas E. This is an open-access article distributed under the terms of the Creative Commons Attribution License, which permits unrestricted use, distribution, and reproduction in any medium, provided the original author and source are credited. 
behaviors and offer support and stress reduction as well as promote political organizing for health services to be provided. Studies in social capital suggest that there is a positive association between social capital and health and that less educated people benefit more [9]. In particular, networks may facilitate the diffusion of health-related information and healthy behaviors more rapidly in egalitarian organizations [11]. Evidence from a systematic review of 148 studies of the association between social relationships and mortality reported that mortality risk associated with lack of social relationships is comparable with well-known risk factors such as smoking [12]. A study of social ties and survival after breast cancer diagnosis showed that socially isolated women had an elevated risk of mortality after diagnosis [13]. Also, a recent study has concluded that contextual, area-level social capital has beneficial effects on individual self-rated health [14].

We suggested that healthcare influences health both directly through treatment options and indirectly through information and support which again affects health through health behaviors and psychosocial factors. Further, we assumed that socioeconomic status indicators, such as education and labor market affiliation, influence health through a number of pathways. Health is thought to be socially determined by access to and use of healthcare and social networks, and by socially determined behaviors. Welfare state policies modify the impact of socioeconomic factors on health. From this background, we aimed to examine and compare the effects of breast cancer treatment on self-rated health among high and low-status women [Figure 1].

We compared the effects of healthcare on self-rated health among women with high and low socioeconomic status in Norway. Healthcare was defined as advanced breast cancer treatment. Norwegian specialized healthcare is public with very few exceptions. This meant that all women in our study would be subject to similar treatment options, regardless of their socioeconomic status. Thus, treatment options were regarded as a constant. Two different surveys were used to construct a data set with one group of women exposed to breast cancer treatment and one group not exposed to breast cancer treatment. All women in the dataset were characterized as either having high or low socioeconomic status, based on educational level and working status. The average effect of breast cancer treatment on self-rated health was estimated by the use of propensity score analysis.

We documented a social gradient in self-rated health among Norwegian women. A gradient was also found in our sample of women exposed to breast cancer treatment. We found that experience of breast cancer illness and treatment moderated the positive correlation between socioeconomic status and self-rated health, as the relative difference in self-rated health between women with high and low socioeconomic status declined after exposure to treatment.

\section{Background Information on Norway}

Norway has one of the highest per capita incomes in the world. It is characterized by an egalitarian distribution of income through redistributive taxation and a broad and generous social security system. 34 percent of the adult population has higher education. In 2009 the unemployment rate was 3.1 percent and the female labor participation rate was 70 percent. The degree of social capital in society is high in terms of social trust, associational membership, and informal interaction [15].

The Norwegian healthcare system is tax financed and is (nearly) free at the point of access. In 2009, approximately 4800 USD per capita was spent on healthcare, which is the second most in the world, and 50 percent above other Scandinavian countries [16]. In 2008, 84 percent of health expenditure was publicly financed. Specialized healthcare is need-based and universal, intended to give people from disadvantaged social groups as equal opportunities to healthcare interventions as any other. There is no second private tier. Individuals would have very limited options to opt up or out of the public system.

Specialized healthcare is organized in four health regions (North, Mid, West, and South-East). By population, South-East is by far the largest health region and is the region with the capital.

A social gradient in health is documented [17]. A recent study showed that educational inequalities in mortality among middle aged people were substantial and increased during the period 1960-2000 [7]. Others have demonstrated a social gradient in breast cancer survival [5]. Breast cancer accounted for 26 percent of all cancers among Norwegian women in 2008, and the 5 years relative survival rate was 87.8 percent. Breast cancer screening and treatment are offered in all health regions.

\section{Materials and Methods}

As the group representing individuals exposed to healthcare intervention we used a sample of women who had been diagnosed with breast cancer and received hospital treatment. Data was self-reported and generated from our 2009 postal questionnaire to 3000 women aged 40-69 who were members of the Norwegian Breast Cancer Association. We included women diagnosed with breast cancer between the years 2000 and 2009, with 2005 as the average time of diagnoses. The response rate was 62 percent. Due to incomplete answers to questions, the final sample consisted of 1666 observations.

To construct a group representing pre-hospitalization status we used data from the 1998 Norwegian Living Conditions Survey of Statistics Norway. The survey is a nationally representative longitudinal survey that in 1998 included the same questions as in our own survey. The 1998 survey was conducted by means of personal interviews by trained personnel. 4871 individuals were invited to participate, response rate was 73 percent. We included all women aged 40-69 who had answered all relevant questions, or 767 observations.

Healthcare was defined as breast cancer treatment and measured by questions on various treatment methods: Breast-conserving surgery; Surgery; Removed >2 lymph nodes; Chemotherapy; Radiation; Long term treatment (hormone); Other treatment. The answers to these questions were not used in the main analysis, but rather in the sensitivity analysis in the last section of the present paper.

Individuals in both treatment group and non-treatment group were assigned a socioeconomic status. Socioeconomic status was defined as High or Low, based on information on education (primary, secondary, and tertiary) and labor market affiliation (given value one if works more than 10 hours a week, 0 otherwise). In egalitarian countries like Norway, income and educational level are imperfectly correlated and educational level is much used as an indicator of socioeconomic status $[7,18,19]$. A higher educational level was assumed to be associated with knowledge of healthy behavior, less occupational restrictions and more job control. It is also shown that working has a positive effect on social status and self-esteem compared to being unemployed, as it increases financial security and offers social networks $[20,21]$.

In the present study, High socioeconomic status was defined as having tertiary education and working more than 10 hours per week. All other combinations of education and labor market affiliation were defined as having Low socioeconomic status. 
Our outcome measure, self-rated health, was measured by the following question: "In general, would you say your health is", and reported on a five-point ordinal scale, ranging from "Very good" to "Very poor". We gave these scores from 5 (Very good) to 1 (Very poor). In the final analysis, self-rated health was treated as a continuous variable, enabling us to calculate the average reported level within a group.

Confounding factors that could be associated with health status and the likelihood of being within the treatment group included Age, Income, Marital status, Organisational membership, and Place. Age controlled for unobserved differences across the women due to their age. In this study, respondents were aged 40-69, and the women were divided into six age groups for the analysis, with a dummy for each age group. Income was reported in six intervals, all measured in NOK: $0-99,000 ; 100,000-199,000 ; 200,000-399,000 ; 400,000-599,000 ; 600,000$ 999,000, and 1 Mill+. For both groups, the majority of respondents were in the income group 200,000-399,999. For the treatment group, income was reported in 2009 for the year they were diagnosed. For the non-treatment group, annual income was reported for 1997, and the reported sums were indexed by the consumer price index to 2005-level. The average year of diagnosis was 2005 for the treatment group. The remaining three variables were seen as network indicators. Marital status was given the value one if married or cohabitant, zero otherwise. Organizational membership was given value one if the respondent was active member in at least one organization (not counting the Norwegian Breast Cancer Association), and zero otherwise. Place controlled for unobserved differences across geographical regions and captured several effects that related to the supply and demand of health services and also to area-level socio-demographic variables (quality of care, travel time to the nearest major hospital, community social capital, educational level, unemployment, voting participation, etc). In this study, the home county of the respondents were aggregated into the four health regions: North; Mid; West; and South-East. We did not have information on health behaviors such as exercise, alcohol consumption, or psychosocial factors such as stress, nor did we have data on previous breast cancer in family or other relevant medical data.

\section{Propensity score matching}

As the treatment-group survey only contained information on self-rated health after treatment, data from the non-treatment-group survey were used to represent self-rated health status before treatment. However, these data could not be compared directly.

There was selection bias into the treatment group survey in three dimensions. First, as the survey was sent to members of the Norwegian Breast Cancer Association, there was a potential selection problem as not all women diagnosed with breast cancer choose to join this association. Second, there could be a selection in who choose to respond to the survey. Third, we only had responses from the survivors in the group of women diagnosed with breast cancer.

To account for this possibility of selection into these data, we applied a propensity score matching approach [21-23]. Based on observable characteristics, each observation in the treatment group data was matched with an observation of the same socioeconomic status in the non-treatment group data. In this manner we were able to compare two similar women and find the unbiased effect of healthcare treatment on self-rated health within each socioeconomic group.

A propensity score was estimated for each individual observation, which is a summary of the covariates (background information) into a scalar. Separately for each socioeconomic group, we estimated a propensity score index for each woman for being in treatment group using a logit regression analysis. This logit analysis was conducted on the basis of individual covariates that were thought to affect both socioeconomic status and self-rated health: Age, income, marital status, organizational membership, and place. As the variables for educational level and labor market affiliation were used for the classification of socioeconomic status, they were included only for the low socioeconomic status groups.

Separately for each socioeconomic status, each individual from the treatment group was matched with an individual from the nontreatment group with the same value of this propensity score scalar. In this manner, counterfactual observations (pre-treatment, self-rated) were constructed based on observable characteristics. The propensity score matching was carried out using the psmatch2 procedure in Stata $[11,22]$, and we used Kernel Matching as the matching algorithm. This matching method gives higher weights to individuals close in terms of propensity scores. Each observation in the non-treatment group was not necessarily used in the matching, and one non-treatment-observation might be matched to several different treatment group-observations, if their propensity scores matched.

The goal of the propensity score matching was to remove the standardized differences between the mean of a variable for the two groups, as expressed in eqn. (1) below. If $\bar{x}$ _denotes the average of a variable over all observations in a sample, and $s$ denotes the standard deviation of that same variable, then the standardized difference is defined as

$$
\text { (1) Std.diff }=\frac{100\left(\bar{x}_{\text {treated }}-\bar{x}_{\text {untreated }}\right)}{\sqrt{\left(s_{\text {treated }}^{2}+s_{\text {untreated }}^{2}\right) / 2}}
$$

The percentage reduction in the bias after matching was measured by eqn. (2) below:

(2) $\%$ bias reduction $=1-\frac{\mid \text { Std } \text {.diff } f_{\text {matched }} \mid}{\mid \text { Std.diff } f_{\text {unmatched }} \mid}$

We estimated ATT (average treatment effect of the treated) for each socioeconomic status group (SES $=\mathrm{H}$ (high) and L (low)) in eqn. (3), which was the average difference in the self-rated health, $y$, for each matched non-treated and treated pair, $i$, and $n$ is the number of pairs.

(3) $A T T_{S E S}=\frac{\sum\left(y_{i, \text { treated }}-y_{i, \text { untreated }}\right)}{n_{\text {treated }}}$

The $A T T_{S E S}$ was expected to be negative for each socioeconomic group, and we were interested in which group had the smallest average reduction in self-rated health. If the reduction in self-rated health was greater in the high socioeconomic status group, $\left|\mathrm{ATT}_{\mathrm{H}}\right|>\left|\mathrm{ATT}_{\mathrm{L}}\right|$, this could be interpreted as exposure to healthcare served to reduce the social gradient in health.

\section{Results}

In total our original sample considered of 2433 women, of whom 68 percent were in the treatment-group and 32 percent were in the non-treatment group. The treated women were in average 4 years older, were more educated ( 47 percent has university education, compared to 25 percent in the non-treatment group), had higher income (18 percent are in the top income groups, compared to 4 percent in the non-treatment group), had more social networks (measured by labor market affiliation, marriage, and membership in organizations), and to a greater extent lived in the central region (South-East) (Table 1). The treated women on average reported lower health scores than the nontreated women, as one would expect. Only 18 percent reported "very 


\begin{tabular}{|c|c|c|c|c|c|c|}
\hline & \multicolumn{3}{|c|}{$\begin{array}{l}\text { Untreated } \\
\text { Socioeconomic status }\end{array}$} & \multicolumn{3}{|c|}{$\begin{array}{l}\text { Treated } \\
\text { Socioeconomic status }\end{array}$} \\
\hline & $\underset{n=767}{\text { All }}$ & $\frac{\text { Low }}{n=613}$ & $\frac{\text { High }}{\mathrm{n}=164}$ & $\underset{\mathrm{n}=1666}{\stackrel{\text { All }}{166}}$ & $\frac{\text { Low }}{\mathrm{n}=967}$ & $\frac{\text { High }}{\mathrm{n}=699}$ \\
\hline Age, mean & 52.2 years & 53.1years & 48.9years & 56.2 years & 57.3years & 55.6years \\
\hline Age $40-44$ years & 23.6 & 20.9 & 33.5 & 7.2 & 4.8 & 10.6 \\
\hline Age $45-49$ years & 20.2 & 19.6 & 22.6 & 13.0 & 11.1 & 15.6 \\
\hline Age $50-54$ years & 20.2 & 19.1 & 24.4 & 20.5 & 19.6 & 21.6 \\
\hline Age $55-59$ years & 14.0 & 14.4 & 12.8 & 23.8 & 23.2 & 24.7 \\
\hline Age $60-64$ years & 10.7 & 12.2 & 4.9 & 20.9 & 23.2 & 17.7 \\
\hline Age $65-69$ years & 11.3 & 13.9 & 1.8 & 14.6 & 18.2 & 9.7 \\
\hline \multicolumn{7}{|l|}{ Educational level (years) } \\
\hline Primary education (0-9) & 25.2 & 32.0 & - & 21.9 & 37.7 & - \\
\hline High school $(10-12)$ & 48.8 & 61.8 & - & 31.5 & 54.3 & - \\
\hline University $(13+)$ & 24.7 & 4.6 & 100.0 & 46.6 & 8.0 & 100.0 \\
\hline \multicolumn{7}{|l|}{ Income, NOK per year } \\
\hline 0-99999 & 16.0 & 18.9 & 4.9 & 4.3 & 6.7 & 0.9 \\
\hline 100000-199999 & 29.0 & 34.6 & 7.9 & 17.4 & 26.5 & 4.9 \\
\hline 200000-399999 & 50.8 & 44.4 & 75.0 & 60.1 & 60.5 & 59.5 \\
\hline $400000-599999$ & 3.6 & 2.0 & 9.8 & 15.2 & 5.7 & 28.5 \\
\hline $600000-999999$ & 0.6 & 0.2 & 2.4 & 2.6 & 0.4 & 5.7 \\
\hline $1 \mathrm{mill}+$ & & - & - & 0.4 & 0.2 & 0.6 \\
\hline Works more than 10 hours a week & 73.1 & 65.9 & 100.0 & 83.9 & 72.2 & 100.0 \\
\hline Has partner (married or cohabitant) & 77.9 & 79.1 & 73.2 & 79.9 & 79.2 & 80.8 \\
\hline$\underline{\text { Is member of organizations }}$ & 57.9 & 54.5 & 70.7 & 68.3 & 65.3 & 72.5 \\
\hline \multicolumn{7}{|l|}{ Geographical health region } \\
\hline North & 11.5 & 11.6 & 11.0 & 12.8 & 13.3 & 12.0 \\
\hline Mid & 16.1 & 16.0 & 16.5 & 13.3 & 13.4 & 13.2 \\
\hline West & 19.2 & 20.1 & 15.9 & 14.8 & 16.4 & 12.6 \\
\hline South-East & 53.3 & 52.4 & 56.7 & 59.1 & 56.8 & 62.2 \\
\hline \multicolumn{7}{|l|}{ Self-assessed health } \\
\hline Very good & 34.1 & 30.0 & 49.4 & 17.8 & 14.7 & 22.2 \\
\hline Good & 42.9 & 43.9 & 39.0 & 43.3 & 43.6 & 42.8 \\
\hline Neither good nor poor & 16.5 & 18.3 & 9.8 & 30.0 & 31.9 & 27.3 \\
\hline Poor & 6.2 & 7.5 & 1.2 & 8.5 & 9.2 & 7.4 \\
\hline Very poor & 0.4 & 0.3 & 0.6 & 0.5 & 0.6 & 0.3 \\
\hline
\end{tabular}

Table 1: Comparisons of the two populations according to individual characteristics. Numbers in percentage unless otherwise stated.

good" health, compared to 34 percent in the non-treatment group [24].

After splitting the groups in two by socioeconomic status, the groups with high socioeconomic status consisted of 699 women from the treatment-group and 164 women from the non-treatment groups. The groups with low socioeconomic status consisted of 967 women from the treatment-group and 603 women from the non-treatment group. By comparing by socioeconomic group in Table 1 , some of the differences between the treatment group and the non-treatment group seemed to cancel out, at least when considering the low-status groups.

There seemed to be a social gradient in self-rated health: A larger proportion of high-status women compared to low-status women rated their health as good or very good in both samples (65 percent versus 58 percent in the treatment group and 88 percent versus 74 percent in the non-treatment group).

Before matching, most variables were statistically significant different between the treatment group and the non-treatment group, within each socioeconomic group. After matching, the bias was drastically reduced, as is seen in the estimate of the column "\% reduced bias" in Table 2, which in all but two cases is positive and high. This indicated that treated and the non-treated women in the new sample shared the same characteristics, and that selection bias had been reduced in the new, matched sample. This meant that we had constructed two similar comparison groups, and could interpret the average difference in self-rated health scores between treated and the non-treated women within a matched pair as the effect of exposure to healthcare intervention. All observations in the unmatched treatment sample were included in the matched sample, which explained why the averages for all variables were identical in the matched and unmatched treatmentgroup samples. However, the matched non-treatment group sample contained multiple observations of several non-treatment observations from the unmatched sample, depending on their propensity score and how that matched the propensity scores of the treatment sample. Thus the average values of the variables in the matched non-treatment sample varied from the unmatched non-treatment sample. There were 699 matched pairs in the high socioeconomic group and 967 matched pairs in the low socioeconomic group.

Figures 2 and 3 show the distribution of the predicted propensity scores according to treatment status and socioeconomic status. A 
Citation: Aas E, Alstadsæter A, Feiring E (2013) Does Healthcare Moderate the Impact of Socioeconomic Status on Self-rated Health? J Clin Res Bioeth 5: 169. doi:10.4172/2155-9627.1000169

Page 5 of 8

\begin{tabular}{|c|c|c|c|c|c|c|}
\hline & \multicolumn{2}{|c|}{ Mean } & \multicolumn{2}{|c|}{$\%$ Difference } & \multicolumn{2}{|c|}{ t-test } \\
\hline & Untreated & Treated & $\%$ bias & $\%$ red. bias & $\mathrm{t}$ & $p>|t|$ \\
\hline \multicolumn{7}{|l|}{ Age 40-44years (gruppe2) } \\
\hline High socioeconomic status, Unmatched & 0.34 & 0.11 & -57.5 & & -7.66 & 0.00 \\
\hline High socioeconomic status, Matched & 0.11 & 0.11 & -0.0 & 99.9 & -0.01 & 0.99 \\
\hline Low socioeconomic status, Unmatched & 0.21 & 0.05 & -49.7 & & -10.3 & 0.00 \\
\hline Low socioeconomic status, Matched & 0.05 & 0.05 & -1.8 & 96.3 & -0.43 & 0.55 \\
\hline \multicolumn{7}{|l|}{ Age 45-49years (gruppe2) } \\
\hline High socioeconomic status, Unmatched & 0.23 & 0.16 & -17.8 & & -2.15 & 0.03 \\
\hline High socioeconomic status, Matched & 0.17 & 0.16 & -4.3 & 75.5 & -0.85 & 0.395 \\
\hline Low socioeconomic status, Unmatched & 0.19 & 0.11 & -23.3 & & -4.62 & 0.00 \\
\hline Low socioeconomic status, Matched & 0.11 & 0.11 & -0.1 & 99.5 & -0.03 & 0.98 \\
\hline \multicolumn{7}{|l|}{ Age 50-54years (gruppe3) } \\
\hline High socioeconomic status, Unmatched & 0.24 & 0.22 & -6.6 & & -0.77 & 0.44 \\
\hline High socioeconomic status, Matched & 0.22 & 0.22 & -1.7 & 74.2 & -0.33 & 0.75 \\
\hline Low socioeconomic status, Unmatched & 0.19 & 0.20 & 1.0 & & 0.20 & 0.88 \\
\hline Low socioeconomic status, Matched & 0.21 & 0.20 & -1.3 & -28.3 & -0.29 & 0.77 \\
\hline \multicolumn{7}{|l|}{ Age 55-59years (gruppe4) } \\
\hline High socioeconomic status, Unmatched & 0.13 & 0.25 & 30.9 & & 3.31 & 0.00 \\
\hline High socioeconomic status, Matched & 0.24 & 0.25 & 3.1 & 90.1 & 0.52 & 0.61 \\
\hline Low socioeconomic status, Unmatched & 0.14 & 0.23 & 23.0 & & 4.33 & 0.00 \\
\hline Low socioeconomic status, Matched & 0.25 & 0.23 & -4.5 & 80.3 & -0.90 & 0.37 \\
\hline \multicolumn{7}{|l|}{ Age 60-64years (gruppe5) } \\
\hline High socioeconomic status, Unmatched & 0.05 & 0.18 & 41.4 & & 4.15 & 0.00 \\
\hline High socioeconomic status, Matched & 0.19 & 0.18 & -5.6 & 86.5 & -0.84 & 0.40 \\
\hline Low socioeconomic status, Unmatched & 0.12 & 0.23 & 28.8 & & 5.40 & 0.00 \\
\hline Low socioeconomic status, Matched & 0.24 & 0.23 & -3.1 & 89.3 & -0.60 & 0.55 \\
\hline \multicolumn{7}{|l|}{ Age 65-69years (gruppe6) } \\
\hline High socioeconomic status, Unmatched & 0.02 & 0.10 & 34.3 & & 3.33 & 0.00 \\
\hline High socioeconomic status, Matched & 0.07 & 0.10 & 13.0 & 62.2 & 2.03 & 0.04 \\
\hline Low socioeconomic status, Unmatched & 0.14 & 0.18 & 11.6 & & 2.22 & 0.03 \\
\hline Low socioeconomic status, Matched & 0.14 & 0.18 & 11.1 & 24.5 & 2.44 & 0.02 \\
\hline \multicolumn{7}{|l|}{ Income $<100000$ NOK per year } \\
\hline High socioeconomic status, Unmatched & 0.05 & 0.01 & -24.2 & & -3.69 & 0.00 \\
\hline High socioeconomic status, Matched & 0.01 & 0.01 & 0.8 & 96.7 & 0.28 & 0.78 \\
\hline Low socioeconomic status, Unmatched & 0.19 & 0.07 & -36.2 & & -7.34 & 0.00 \\
\hline Low socioeconomic status, Matched & 0.07 & 0.07 & -1.0 & 97.2 & -0.29 & 0.78 \\
\hline \multicolumn{7}{|l|}{ Income 100000-199999 NOK per year } \\
\hline High socioeconomic status, Unmatched & 0.08 & 0.05 & -12.5 & & -1.56 & 0.12 \\
\hline High socioeconomic status, Matched & 0.07 & 0.05 & -10.7 & 14.2 & -2.04 & 0.04 \\
\hline Low socioeconomic status, Unmatched & 0.35 & 0.26 & -17.8 & & -3.47 & 0.00 \\
\hline Low socioeconomic status, Matched & 0.27 & 0.26 & -1.7 & 95.3 & -0.19 & 0.85 \\
\hline \multicolumn{7}{|l|}{ Income 200000-399999 NOK per year } \\
\hline High socioeconomic status, Unmatched & 0.75 & 0.60 & -33.4 & & -3.71 & 0.00 \\
\hline High socioeconomic status, Matched & 0.63 & 0.60 & -6.8 & 79.6 & -1.21 & 0.23 \\
\hline Low socioeconomic status, Unmatched & 0.45 & 0.60 & 32.2 & & 6.22 & 0.00 \\
\hline Low socioeconomic status, Matched & 0.60 & 0.60 & 1.7 & 94.8 & 0.37 & 0.71 \\
\hline \multicolumn{7}{|l|}{ Income 400000-599999 NOK per year } \\
\hline High socioeconomic status, Unmatched & 0.10 & 0.28 & 28.9 & & 5.05 & 0.00 \\
\hline High socioeconomic status, Matched & 0.24 & 0.28 & 12.7 & 74.0 & 2.08 & 0.04 \\
\hline Low socioeconomic status, Unmatched & 0.02 & 0.06 & 19.3 & & 3.52 & 0.00 \\
\hline Low socioeconomic status, Matched & 0.06 & 0.06 & -2.1 & 88.9 & -0.38 & 0.70 \\
\hline \multicolumn{7}{|l|}{ Income 600000-999999 NOK per year } \\
\hline High socioeconomic status, Unmatched & 0.02 & 0.06 & 16.6 & & 1.72 & 0.09 \\
\hline High socioeconomic status, Matched & 0.06 & 0.06 & 1.0 & 93.7 & 0.17 & 0.87 \\
\hline Low socioeconomic status, Unmatched & 0.002 & 0.004 & 4.6 & & 0.85 & 0.40 \\
\hline Low socioeconomic status, Matched & 0.003 & 0.004 & 1.6 & 64.9 & 0.31 & 0.75 \\
\hline
\end{tabular}

Has partner (married or cohabitant) 
Citation: Aas E, Alstadsæter A, Feiring E (2013) Does Healthcare Moderate the Impact of Socioeconomic Status on Self-rated Health? J Clin Res Bioeth 5: 169. doi:10.4172/2155-9627.1000169

Page 6 of 8

High socioeconomic status, Unmatched High socioeconomic status, Matched

Low socioeconomic status, Unmatched

Low socioeconomic status, Matched

Is member of organizations

High socioeconomic status, Unmatched

High socioeconomic status, Matched

Low socioeconomic status, Unmatched

Low socioeconomic status, Matched

Health region North

High socioeconomic status, Unmatched

High socioeconomic status, Matched

Low socioeconomic status, Unmatched

Low socioeconomic status, Matched

Health region Mid

High socioeconomic status, Unmatched

High socioeconomic status, Matched

Low socioeconomic status, Unmatched

Low socioeconomic status, Matched

Health region West

High socioeconomic status, Unmatched

High socioeconomic status, Matched

Low socioeconomic status, Unmatched

Low socioeconomic status, Matched

Health region South-East

High socioeconomic status, Unmatched

High socioeconomic status, Matched

Low socioeconomic status, Unmatched

Low socioeconomic status, Matched

\subsection{3}

0.81

0.79

0.79

0.71

0.74

0.55

0.65

0.11

0.12

0.12

0.14

0.16

0.11

0.15

0.11

0.16

0.11

0.20

0.18

0.67

0.52

0.57

$\mathbf{0 . 8 1}$
$\mathbf{0 . 8 1}$
0.79
0.79

\section{2}

0.6

0.03

$-0.7$

4.0

$-3.0$

0.73

0.65

0.65

0.12

0.12

0.13

0.13

0.13

0.13

0.13

0.13

0.13

0.13

0.16

0.16

0.62

0.62

0.57

0.57

1.4

1.4

5.2

$-1.3$

$-9.3$

6.0

7.0

5.5

$-9.3$

5.1

$-9.4$

$-4.0$

$\begin{array}{lcl} & \mathbf{2 . 1 9} & \mathbf{0 . 0 3} \\ \mathbf{9 6 . 7} & \mathbf{0 . 1 2} & \mathbf{0 . 9 1} \\ & 0.05 & 0.96 \\ 153.6 & -0.15 & 0.88 \\ & & \\ & & \\ 24.8 & \mathbf{0 . 4 6} & \mathbf{0 . 6 4} \\ & -0.57 & \mathbf{0 . 5 7} \\ 93.6 & 4.18 & 0.00 \\ & 0.31 & 0.76\end{array}$

0.37

0.71

55.8

0.27

0.79

75.5

1.02

0.31

0.79

35.6

$-1.10$

0.27

$1.22 \quad 0.22$

$-1.34$

20.8

1.30

0.19

45.9

$-1.11$

0.27

$1.03 \quad 0.30$

$-1.87$

0.06

57.7

$-0.89$

0.37

Table 2: Differences in outcome variables before and after matching.

$\begin{array}{cccc}11.2 & & \mathbf{1 . 3 1} & \mathbf{0 . 1 9 2} \\ -8.9 & 21.2 & -1.70 & 0.09 \\ 8.8 & & 1.70 & 0.09 \\ 0.0 & 99.9 & 0.00 & 1.00\end{array}$

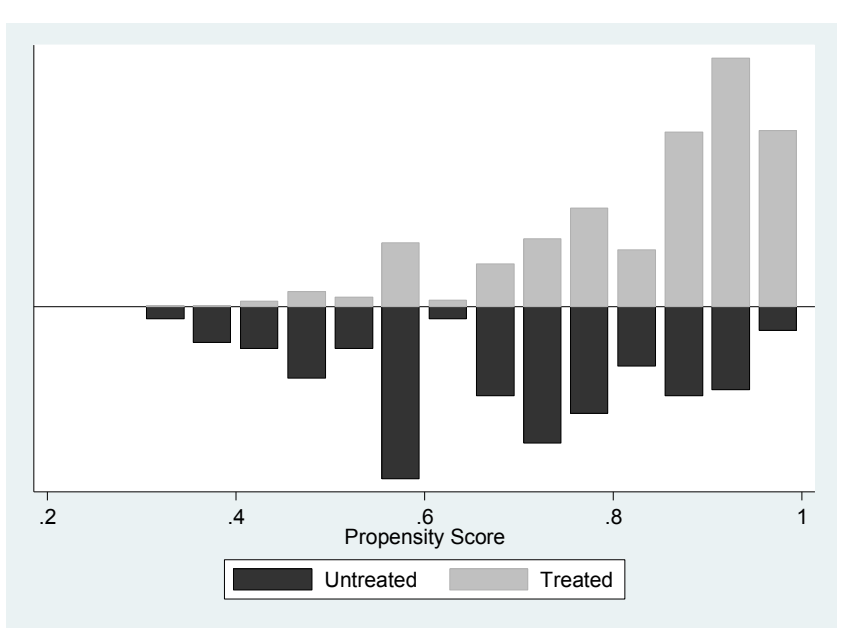

Figure 2: Overlap between treated and untreated for high socioeconomic status.

condition for using this method is that there is sufficient overlap in the propensity scores in the two groups. There was a large degree of overlap between the distributions. For values of the propensity score higher than 0.8 (0.6) in the high (low) socioeconomic status group, the number of individuals was higher than the number of individuals in the general population. Remember also that the total number of observations was higher in the treatment sample than in the non- treatment sample.

The $A T T_{\text {SES }}$ was estimated separately for the high and low socioeconomic groups, and the results are reported in Table 3. Both groups experienced a reduced level of self-rated health following healthcare treatment for breast cancer, and the estimated $A T T_{S E S}$ were significant for both groups. The high-status women on average reported a 0.63 points reduction in health, while the corresponding reduction 


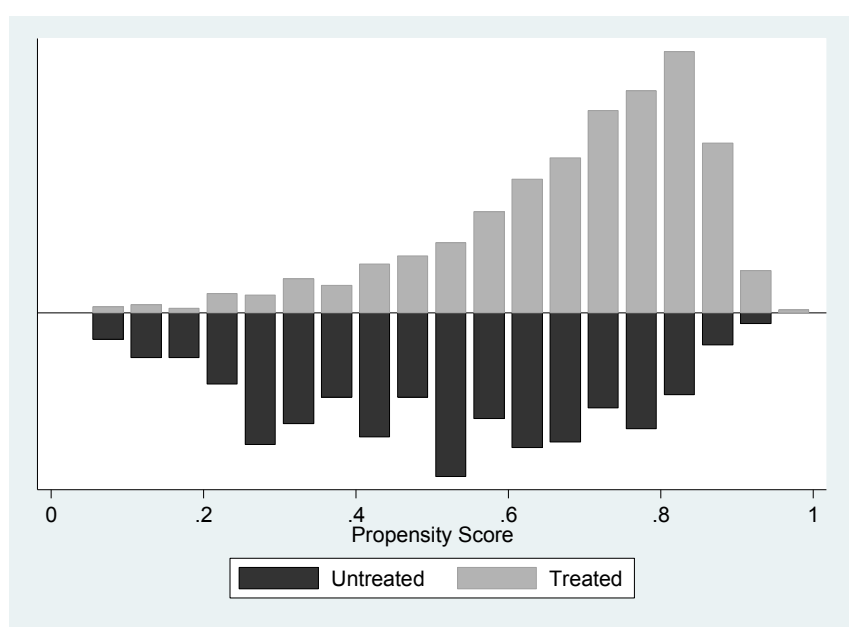

Figure 3: Overlap between treated and untreated for low socioeconomic status.

$\begin{array}{lcccc} & \text { Difference } & \text { Bias } & \text { Std.error* } & 95 \% \mathrm{Cl} \\ \begin{array}{l}\text { High socioeconomic status } \\ \text { ATT }\end{array} & -0.63 & -0.002 & 0.122 & (-0.8823,-0.2166) \\ \text { Low socioeconomic status } & & & & \\ \quad \text { ATT } & -0.32 & -0.0032 & 0.062 & (-0.4542,-0.2283)\end{array}$

Table 3: Average treatment effect among the treated (ATT) according to socioeconomic status.

in for the low status women was 0.32 points. As $\left|\mathrm{ATT}_{\mathrm{H}}\right|>\left|\mathrm{ATT}_{\mathrm{L}}\right|$, we can conclude that experience of breast cancer illness and treatment modified the social gradient in health.

\section{Discussion and Conclusions}

We documented a social gradient in self-rated health among Norwegian women. A gradient was also found in our sample of women exposed to breast cancer treatment. We found that experience of breast cancer illness and treatment moderated the positive correlation between socioeconomic status and self-rated health, as the relative difference in self-rated health between women with high and low socioeconomic status declined after exposure to treatment.

The methodological strengths in this study lie first and foremost in the utilization of the Norwegian universal one-tier healthcare design. The individual has limited option to opt up or out of the system. Hence, all individuals in our study would be subject to similar treatment options, regardless of their socioeconomic status, and we were able to treat healthcare as a constant. Secondly, we adopted a propensity score match approach to correct for sample selection bias due to observable differences between treatment and the non-treatment groups. The strength of propensity score matching methods is the explicit counterfactual framework that is offered. We are not aware of any study of the impact of healthcare on the social gradient in health that shares these features. However, there are some potential challenges to our approach. There might be relevant covariates that we do not observe in the dataset, which could affect the propensity matching (as pointed out in the Methods section). Also, although the Norwegian healthcare system is a public one-tier system and cancer treatment is offered to all patients with a breast cancer diagnosis regardless of socioeconomic status, we still cannot rule out the possibility that high-status women are treated faster and get more extensive treatment than low-status women. We also cannot rule out that there might be women in the non-treatment group that had experienced healthcare intervention due to breast cancer or other serious illness. A general challenge in the literature that is not specific to the present study is that self-rated health is an individual specific figure and cannot necessarily be compared across individuals. In spite of these challenges, we argue that our results are reliable.

The major findings of our study can be summarized as follows: First, a social health gradient was found as self-rated health scores were lower among women with low socioeconomic status than among women with high socioeconomic status. Such a social gradient in self-perceived health was found both among women in the general Norwegian population and among women treated for breast cancer. Second, breast-cancer illness and treatment had a moderating effect on the social gradient in health. Third, illness and treatment seemed to modify the effect of social status on self-rated health more for the least advantaged. Further studies are needed to generalize outside the Norwegian context. Contextual limitations include the diversity of societies' social relationships and area-specific environments, of healthcare systems, and of welfare state arrangements.

These results lend some support to the hypothesis that individuals from lower status groups benefit from healthcare more than others. It is plausible that healthcare may substitute for lack of information and knowledge but there are pathways and mechanisms accounting for these associations we are not able to explain in the present study. When deciding whether to put resources into healthcare or alternatively to other policy areas to lessen the health gradient, one would need an estimate of the likely impact of treatment on the health gradient. Further studies may be needed to measure a reduction in inequalities in terms of morbidity and mortality [25].

\section{Acknowledgements}

We thank the Norwegian Cancer Association and the Faculty of Medicine at University of Oslo for financing. Hope Corman, Tor Iversen, Hans Olav Melberg and anonymous referees have provided valuable comments and suggestions, as have conference participants at Workshop on Social Capital and Health in Oslo, September 2010, and at iHEA's 8th World Congress on Health Economics in Toronto, July 2011. We thank the Norwegian Breast Cancer Association for assisting with the postal survey, and we in particular thank all women who took the time and effort to complete and return the survey. Ethical approval was granted for this study by the Norwegian Regional Committee for Medical Research Ethics REK S-090236.

\section{References}

1. Berkman LF, Kawachi I (2000) Social epidemiology. Oxford University Press, New York.

2. Marmot MG, Wilkinson RG (2006) Social determinants of health. Oxford University, New York.

3. Marmot MG (2011) Interim second report on social determinants of health and the health divide in the WHO European Region. WHO Regional Office for Europe, Copenhagen.

4. Iversen T (2008) An exploratory study of associations between social capital and self-assessed health in Norway. Health Econ Policy Law 3: 349-364.

5. Mackenbach JP, Stirbu I, Roskam AJ, Schaap MM, Menvielle G, et al. (2008) Socioeconomic inequalities in health in 22 European countries. N Engl J Med 358: 2468-2481.

6. Kondo N, Sembajwe G, Kawachi I, van Dam RM, Subramanian SV, et al. (2009) Income inequality, mortality, and self rated health: meta-analysis of multilevel studies. BMJ 339: b4471.

7. Strand BH, Grøholt EK, Steingrímsdóttir OA, Blakely T, Graff-Iversen S, et al. (2010) Educational inequalities in mortality over four decades in Norway: prospective study of middle aged men and women followed for cause specific mortality, 1960-2000. BMJ 340: c654 
Citation: Aas E, Alstadsæter A, Feiring E (2013) Does Healthcare Moderate the Impact of Socioeconomic Status on Self-rated Health? J Clin Res Bioeth 5: 169. doi:10.4172/2155-9627.1000169

Page 8 of 8

8. Kim MH, Kim CY, Park JK, Kawachi I (2008) Is precarious employment damaging to self-rated health? Results of propensity score matching methods using longitudinal data in South Korea. Soc Sci Med 67: 1982-1994.

9. Scheffler RM, Brown TT (2008) Social capital, economics, and health: new evidence. Health Econ Policy Law 3: 321-331.

10. 10 Scheffler RM, Brown TT, Rice JK (2007) The role of social capital in reducing non-specific psychological distress: the importance of controlling for omitted variable bias. Soc Sci Med 65: 842-854.

11. Aida J, Hanibuchi T, Nakade M, Hirai H, Osaka K, et al. (2009) The different effects of vertical social capital and horizontal social capital on dental status: a multilevel analysis. Soc Sci Med 69: 512-518.

12. Holt-Lunstad J, Smith TB, Layton JB (2010) Social relationships and mortality risk: a meta-analytic review. PLoS Med 7: e1000316.

13. Kroenke CH, Kubzansky LD, Schernhammer ES, Holmes MD, Kawachi I (2006) Social networks, social support, and survival after breast cancer diagnosis. J Clin Oncol 24: 1105-1111.

14. Kim D, Baum CF, Ganz ML, Subramanian SV, Kawachi I (2011) The contextual effects of social capital on health: a cross-national instrumental variable analysis. Soc Sci Med 73: 1689-1697.

15. Islam MK, Merlo J, Kawachi I, Lindström M, Burström K, et al. (2006) Does it really matter where you live? A panel data multilevel analysis of Swedish municipality-level social capital on individual health-related quality of life. Health Econ Policy Law 1: 209-235.

16. OECD (2010) Health Policy Data
17. Kravdal $\varnothing ~(2000)$ Social inequalities in cancer survival. Population Studies 54 1-18.

18. Krokstad S, Westin S (2004) Disability in society-medical and non-medical determinants for disability pension in a Norwegian total county population study. Soc Sci Med 58: 1837-1848.

19. Bjelland I, Krokstad S, Mykletun A, Dahl AA, Tell GS, et al. (2008) Does a higher educational level protect against anxiety and depression? The HUNT study. Soc Sci Med 66: 1334-1345.

20. Quesnel-Vallée A, DeHaney S, Ciampi A (2010) Temporary work and depressive symptoms: a propensity score analysis. Soc Sci Med 70: 1982-1987.

21. Rosenbaum PR, Rubin DB (1983) The Central Role of the Propensity Score in Observational Studies for Causal Effects. Biometrika 70: 41-55.

22. Leuven E, Sianesi B (2003) PSMATCH2: Stat module to perform ful Mahalanobis and propensity score matching common support graphing and covariate imbalance testing. http:/ideasrepecorg/c/bocode/s432001html

23. Jones AM, Rice N, D'Uwa TB, Balia S (2007) Applied Health Economics. Routledge, New York.

24. d'Uva TB, O'Donnell O, van Doorslaer E (2008) Differential health reporting by education level and its impact on the measurement of health inequalities among older Europeans. Int J Epidemiol 37: 1375-1383.

25. Idler EL, Benyamini Y (1997) Self-rated health and mortality: a review of twentyseven community studies. J Health Soc Behav 38: 21-37. 